\title{
Sexual trauma associated with fisting and recreational drugs
}

\author{
C E Cohen, A Giles, M Nelson
}

Sex Transm Infect 2004;80:469-470. doi: 10.1136/sti.2004.011171

There is a rising trend in high risk sexual behaviour among men who have sex with men (MSM), with concomitant use of recreational drugs. Activities include fisting and unprotected anal intercourse with a partner who is HIV serodiscordant or of unknown status. We describe three cases of HIV positive MSM who have recently attended our unit as a result of complications secondary to fisting.

$\mathrm{T}$ here have been several reports citing rising trends in high risk sexual behaviour among men having sex with men (MSM), with concomitant use of recreational drugs such as ecstasy, crystal methamphetamine, cocaine, ketamine, and poppers. ${ }^{1-3}$ Activities include fisting and unprotected anal intercourse with a partner who is HIV serodiscordant or of unknown status. In the United Kingdom, there have also been increases in the incidence of sexually transmitted infections in MSM, which in themselves are markers of unsafe sexual practices. ${ }^{4}$ At the same time within our unit, the incidence of hepatitis C in HIV positive MSM has risen, with unprotected anal intercourse a probable risk factor. ${ }^{5}$ We describe three HIV positive MSM who have recently attended our unit as a result of complications secondary to fisting.

\section{CASE REPORTS}

\section{Case 1}

A 39 year old man with a 19 year history of HIV, presented to a casualty department 14 hours after being fisted at a party with four other men. During the evening he had snorted ketamine and used some rectally. While being fisted, a "pop" was heard and the partner stopped immediately. He began bleeding per rectum and 3 hours later developed abdominal pain and bloating, which increased in severity, prompting him to attend hospital. On arrival his abdomen was distended with guarding in the left iliac fossa. A chest radiograph revealed free air under the diaphragm (fig 1). At emergency laparotomy $550 \mathrm{ml}$ of fresh blood was found within the peritoneal cavity together with a $1 \mathrm{~cm}$ full thickness laceration of the lower sigmoid colon. This was successfully repaired and he made an uneventful recovery.

\section{Case 2}

A 37 year old man, recently diagnosed as HIV positive, travelled to London for an organised weekend fisting circuit party with two other HIV positive men. During the evening he inhaled poppers, took ecstasy, and consumed one quarter of a gram of ketamine. Five hours into the party, while being fisted, a "rip" was felt, the activity stopped and the patient noted slight rectal bleeding. However, after douching himself, he began bleeding profusely from the rectum and developed severe central abdominal pain. He presented to the casualty department within 50 minutes by which time he had abdominal peritonism. A Hartmann's procedure was performed and revealed $600 \mathrm{ml}$ of fresh blood in the peritoneal cavity with a $10 \mathrm{~cm}$ upper rectal tear. His colostomy has since been reversed.

\section{Case 3}

The final patient is a 54 year old man with a 4 year history of HIV who attended a private party, where he inhaled poppers, snorted ketamine, and smoked some cannabis. His partner had inserted his hand, arm, and a $15 \mathrm{~cm}$ rubber dildo into the rectum and further into the sigmoid colon. At this point, the patient felt immediate central abdominal pain as if he had been "punched," which persisted despite analgesia. There was no rectal bleeding even after cold douching. Thirty six hours after the event, he was admitted as a surgical emergency with peritonitis. Two colonic perforations were found at operation; the first at the rectosigmoid junction and the second more proximally in the mid-sigmoid colon. A defunctioning loop ileostomy was performed which has since been successfully reversed.

\section{DISCUSSION}

Patients may delay their presentation because of embarrassment, fear of stigmatisation, or ignorance regarding the seriousness of their symptoms. ${ }^{6}$ Physicians therefore need to be aware of the complications that can result from fisting and use of foreign bodies in the rectum, ranging from rectal bleeding and pain to overt peritonitis. In order to diagnose the cause accurately, a sensitive approach in gaining the history is mandatory, which will otherwise omit valuable clues. ${ }^{67}$

These patients highlight concerns regarding unsafe sexual behaviour in some MSM, under the influence of drugs which increase the duration of sexual activity. They sustained significant injuries but were unaware of the symptoms of

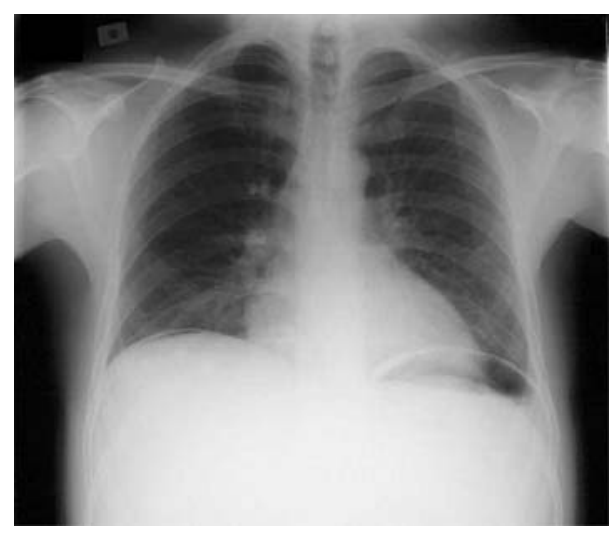

Figure 1 Chest radiograph demonstrating free air under the diaphragm indicative if an intestinal perforation. 


\section{Key messages}

- Fisting carries a risk of colorectal perforation

- Recreational drugs can prolong the duration of sexual activity thereby increasing this risk

- Patients need more information regarding safe fisting and how to avoid transmission of infection with this practice

colorectal perforation, despite engaging in fisting for many years. Had they delayed their presentations further, the outcome could have been fatal. ${ }^{8-10}$ It is important to state however, that many MSM do practise fisting safely using latex gloves and lubricant and follow recommended guidelines. The use of a "safe word" before starting may ensure that both parties can stop at any point when discomfort is felt. ${ }^{11}$ Findings from the UK Gay Men's Sex Survey 2002 showed that overall, $12.8 \%$ of respondents had engaged in fisting within the preceding 12 months. Among men who had reported receptive anal intercourse in that time period, those who had also been fisted were more likely to have had unprotected anal intercourse $(70.7 \%)$ than those who had not been fisted $(50.7 \%){ }^{12}$ However, few reports on this subject that emphasise the possibility of transmitting infectious diseases and the potential surgical sequelae reach MSM.

The cases described have therefore prompted our unit to actively pass on more information to both our genitourinary medicine and HIV patients regarding the complications associated with this practice.

\section{CONTRIBUTORS}

CC collected data and wrote the paper; AG and MN contributed to writing the paper.

\section{Authors' affiliations}

C E Cohen, A Giles, M Nelson, Department of HIV Medicine, Kobler Outpatient Clinic, Chelsea and Westminster Hospital, 369 Fulham Road, London SW10 9NH, UK

Source of funding: nil.

Conflict of interest: nil.

Correspondence to: Dr C E Cohen, St Stephen's Centre, 2nd floor, Chelsea and Westminster Hospital, 369 Fulham Road, London SW10 9NH, UK; cemcohen@hotmail.com

Accepted for publication 24 July 2004

\section{REFERENCES}

1 Romanelli F, Smith KM, Thornton AC, et al. Poppers: epidemiology and clinical management of inhaled nitrite abuse. Pharmacotherapy 2004;24:69-78.

2 Lee SJ, Galanter M, Dermatis, et al. Circuit parties and patterns of drug use in a subset of gay men. J Addict Dis 2003;22:47-60.

3 Mettey A, Crosby R, DiClemente RJ, et al. Associations between internet sex seeking and STI associated risk behaviours among men who have sex with men. Sex Transm Infect 2003;79:466-8

4 Health Protection Agency. Renewing the focus, HIV and other sexually transmitted infections in the United Kingdom in 2002, an update November 2003 www.hpa.org.uk.

5 Browne R, Asboe D, Gilleece Y, et al. Increasing incidence of acute hepatitis C in HIV positive men secondary to sexual transmission: a new epidemic. Poster presentation at 9th European Aids Conference (EACS), 25-29 October, 2003, Warsaw Abstract EA972.

6 Spears K, Hutson H, Atluri S. Rectal perforation following manual-anal intercourse. Acad Emerg Med 1995;2:852-3.

7 Irizarry E, Gottesman L. Rectal sexual trauma including foreign bodies. Int J STD AIDS 1996;7:166-9.

8 Torre C. Delayed death from fisting. Am J Forens Med Pathol 1987:8:91.

9 Fain DB, McCormick GM. Vaginal fisting as a cause of death. Am J Forens Med Pathol 1989;10:73-5.

10 Reay D, Eisele J. Sexual abuse and death of an elderly lady by "fisting" Am J Forens Med Pathol 1983;4:347-9.

11 The Terrence Higgins Trust. The bottom line-a handbook. Produced by The Terrence Higgins Trust as part of the Community HIV and AIDS Prevention Strategy (CHAPS) January 2003, www.tht.org.uk.

12 Hickson F, Weatherburn P, Reid D, et al. Out and about: findings from the United Kingdom Gay Men's Sex Survey 2002. London: Sigma Research, December 2003. 